\title{
OTRA ATLÁNTIDA. A PROPÓSITO DE UNA PROFECÍA QUE ASPIRA A AUTOCUMPLIRSE
}

MANUEL CRUZ

UNIVERSIDAD DE BARCELONA

Pronto se cumplirán treinta años de la afirmación althusseriana "Marx ha descubierto un nuevo continente, el continente historia". El continente parece haberse hundido, como una nueva Atlántida, en las aguas del presente. Desde diversos frentes se decreta o se constata el final de la historia, el agotamiento de la modernidad, la crisis de los grandes relatos... anuncios todos ellos que, al margen de los matices diferenciales, se diría que son coincidentes en su rechazo de la dimensión histórica del discurso marxiano. Parece procedente, por tanto, empezar preguntándonos: ¿era ésa realmente la especificidad de Marx?, ¿lo definía dicha atención por la historia como moderno, de manera que podamos afirmar que la crisis de la modernidad es también su crisis?

Quisiera dejar sentado desde el principio el lugar estratégico de esta discusión. No estoy proponiendo centrarnos en la historia por mero prurito filológico. A mi modo de ver, la reflexión acerca de la historia es en este momento una reflexión inevitable, necesaria, conveniente y probablemente ejemplar en el sentido de que en la tematización del asunto historia confluyen las líneas mayores de lo que se está pensando y se puede pensar hoy. Detengámonos, por ejemplo, en las polémicas a propósito del final de la historia. Discutir sobre el final de la historia implica discutir sobre la vigencia o no vigencia de ciertas concepciones del mundo. $\mathrm{O}$, con palabras ajenas, de la obsolescencia o no de las maquinarias productoras de sentido. El tema de la historia tiene este carácter de encrucijada, es fronterizo con muchos discursos (con la ética, con la historiografía, con la metodología de las ciencias sociales). Desde esta perspectiva, la crisis de la filosofía de la historia, si la hubiera (o cuando menos los apuros), debiera verse como un episodio clave de la crisis de nuestro tiempo.

Y el aspecto de esta crisis de nuestro tiempo que más atañe (o daña) a la historia es, qué duda cabe, lo que Lyotard, y después otros, han llamado la crisis de los grandes relatos de legitimación y, muy en especial, del marxismo, que era el que hacía una apuesta más decidida por la posibilidad del conocimiento científico de la historia. Hay que decir que esta crisis no es de ahora, 
de la caída del Muro, sino que, desde el punto de vista filosófico, hace por lo menos 20 años que empezó el proceso de cuestionamiento; que a mediados de los 70 aparecieron los entonces llamados nuevos filósofos, y que, desde el punto de vista estructural, los elementos causales (fundamentalmente la reactivación de la economía capitalista) aparecieron a principios de los 80 . Pero, de la misma forma que en el nivel popular el presunto fracaso del marxismo se visualiza con la caída del Muro, también la actitud dinamitadora de la historia, aunque viene de antes (por lo menos de Nietzsche y su segunda intempestiva, "Sobre la utilidad de los estudios históricos para la vida"), se identifica con el aldabonazo de Fukuyama, que, como mínimo, ha tenido la virtud de colocarnos ante la ostentosa e inesquivable evidencia de nuestros supuestos acerca de la historia.

¿Y qué viene a decirnos Fukuyama? A estas alturas, es difícil que alguien lo ignore. ${ }^{1}$ En resumidas cuentas: nada hay por hacer y nada hay por pensar. Si la formulación pareciera excesivamente rotunda, podría hacerse una breve incursión en el capítulo de las puntualizaciones, pero sospecho que lo sustancial del enunciado no cambiaría. Así, la presunta puntualización según la cual el final de la historia no significa el final de los acontecimientos del mundo no aporta, a mi modo de ver, ningún elemento nuevo. En primer lugar, porque la aparente concesión según la cual algunas sociedades siguen estando en la historia tiene algo de farisaico: todavía, habría que decir mejor, están en ella, pero con su fecha de caducidad impresa en el dorso. Cuando lleguen a cierto grado de desarrollo político, sea por su propio convencimiento o por presiones ajenas, ninguna otra cosa les será dado esperar. Pero es que, en segundo lugar, por grandes y trascendentales que fueran los acontecimientos que aguardaran en el futuro, no cabe plantearse ideas alternativas al liberalismo para interpretarlos. Por tanto: se ha acabado la potestad - la tuviera quien la tuviera- de determinar el sentido de la historia. La propuesta, ciertamente, nos pilla en el peor momento porque frente a esto resulta francamente difícil intentar oponer firmísimas convicciones. Por expresarlo de la manera plástica en que lo hacía aquel personaje cinematográfico (de El declive del imperio americano): ya no hay nada que podamos señalar mientras decimos "así queremos vivir".

Pero hagamos por un momento filosofía de la historia-ficción: si no se hubiera hundido el socialismo real (si hubiera, por tanto, dónde señalar, aunque fuera a regañadientes), ¿qué se hubiera dicho de las tesis de Fukuyama? Seguramente, se habrían alzado voces que afirmaran que la mera existencia de esas sociedades, empeñadas en edificar un modo de producción alternativo, probaba la falsedad de dichas tesis. ¿Hubiera significado

1 Tras el famoso artículo del National Interest (verano del 89), Francis Fukuyama ha presentado en forma más elaborada y explícita su posición en el libro El fin de la historia y el último hombre, Planeta, Barcelona, 1992. 
esta respuesta un rechazo absoluto de ellas? Me temo que no: quienes consideraban el comunismo el modo de producción irrebasable, insuperable, en el fondo estaban diciendo "final, sí, pero todavía no", lo cual en modo alguno implica pensar de otra manera. El ejemplo imaginario pretende introducir una sospecha de alcance respecto a la naturaleza misma de la reflexión histórica. Fukuyama y buena parte de sus críticos parecen compartir idéntica idea de la historia y, por extensión, de su final. Una idea que, en cuanto tal, no tiene su origen en la oscuridad de los tiempos primordiales, sino muy cerca de nosotros, en pleno siglo XVIII, cuando la Ilustración empieza a pensarse en formas secularizadas, en términos de historia universal y mundial. Hasta ese momento lo único que cabía pensar era un plan divino respecto al conjunto del acontecer mundial. Lo que entonces empieza a llamarse "filosofía de la historia" viene a representar la secularización de la providencia divina, el intento de perpetuar la idea de que existe una mano invisible que orienta y guía el acontecer histórico hacia una causa final. Marx estaría culminando, en esta interpretación, el proceso abierto con Voltaire. La idea del final de la historia, por su parte, también pertenecería a la escatología secularista de la Ilustración, que creyó tener al alcance de la mano la vuelta a la Edad de Oro. Borrado el pecado original por la madurez y la emancipación definitivas del ser humano, se reconciliaría la humanidad consigo misma, perdería su sentido todo lo anterior, condenado como historia natural del hombre o prehistoria, y sería la tierra un paraíso.

Vale la pena llamar la atención en que este tipo de formulaciones, at nque planteadas de esta forma parezcan cosa de especialistas, han terminads por impregnar profundamente la mentalidad del hombre occidental conte nporáneo. Más aún, incluso muchas de las críticas a todo este esquema g:obal parecen conservar adherencias de lo criticado. Así, afirmaciones del tipo "el futuro ya ha llegado", "el acontecimiento esperado ya queda atrás", "vivimos en la poshistoria", etc., cuyo uso se ha convertido hoy en moneda corriente, dan por supuesta -0 , como mínimo, su inteligibilidad la exigela existencia de las entidades por fin superadas, lo que, por lo menos desde el punto de vista de los críticos, debería estar lejos de ser obvio. Pero, por cierto, ¿desdé qué lugar teórico queda garantizada dicha existencia?, ¿qué sabemos en concreto de la naturaleza de aquello que unos esperaban y otros han superado?

La respuesta a ambas preguntas sólo puede ser negativa (ningún lugar teórico la garantiza y apenas sabemos nada, respectivamente), lo que no deja de ser útil al propósito de eșta exposición. Porque nos coloca ante la evidencia de que, efectivamente, subyace en nuestra concepción de la historia una imagen de origen judeocristiano en la que la humanidad se nos aparece siempre en camino hacia algún sitio, siempre por determinar. Habría un libro sagrado que garantizaría la existencia de ese sitio y, eventualmente, su ubicación. Y sería ese mismo gran libro sagrado el que nos aseguraría, 
no ya sólo que habrá un futuro, sino incluso cómo será. Desde esta óptica, que de puro arraigada ha terminado por convertirse en el sentido común dominante, resulta inconcebible que se pudiera pasar de largo ante él, que el futuro pudiera haber ocurrido sin que nos enteráramos. ${ }^{2}$ Como es obvio, a medida que este esquema se seculariza, su eficacia tiende a rebajarse de modo inexorable. En ese sentido, aquella reacción frente al dictamen de Fukuyama podemos valorarla tan coherente como de orden: ien nombre de qué o de quién aceptar, pongamos por caso, que ya estamos en el fin de la historia?

Pero hay que dar un paso más y enunciar la pregunta alternativa: ¿en nombre de qué o de quién aceptar que el fin de la historia será, sólo que un poco más tarde? Discutir sobre la ubicación precisa del momento de la clausura es moverse en el interior de un mismo marco conceptual. De ahí la afirmación anterior: decir "fín, sí, pero todavía no", en modo alguno implica pensar de otra manera. Es permanecer en el interior de una concepción del relato histórico entendido como la historia del poder, como el relato escrito desde la óptica de aquellos que finalmente han hecho realidad su proyecto. ${ }^{3} \mathrm{O}$ mejor: lo que ha terminado sucediendo es el lugar desde el que reconstruir el pasado. Tal vez sea esa coincidencia en lo profundo lo que explique la rápida asimilación — por más que sea polémica- del mensaje de los hegelianos de derecha de hoy. La inmensa mayoría de críticos ha discrepado del contenido, apenas unos pocos ${ }^{4}$ han declarado no entender aquello que se les anunciaba.

Por supuesto que la rotundidad en la formulación no debiera llevarnos a confundir a Hegel con Fukuyama, y a ambos con Marx. En el planteamiento marxista no se habla de final de la historia, sino más bien de inicio de la historia propiamente dicha (y final, si acaso, de la prehistoria). Sin embargo, subsisten algunas dificultades que hacen en cierto modo allegables los tres enfoques. Porque el problema es: una vez que se ha alcanzado el modo de

2 Puede resultar pertinente en este punto hacer una referencia, aunque sea fugaz, a lo que Marramao ha denominado el equivoco antropocéntrico que se inicia con el Renacimiento. Así, se lee en Poder y secularización: "el hombre de la Modernidad es mucho más hijo del mensaje cristiano que del humanismo antiguo. La crítica actual (que en el campo histórico-artístico se ha anticipado a los historiadores políticos y sociales) ha aclarado desde hace décadas que el Renacimiento arraigaba en el pasado, en la tradición cristiana medieval, y que su antigüedad era en realidad helenística, recuperada de un crisol de problemas en el cruce de diversas culturas" (G. Marramao, Poder y secularización, Península, Barcelona, 1989, p. 114).

${ }^{3}$ Cuando Benjamin se pregunta, en su tesis VI de Filosofía de la Historia, cit., con quién se compenetra el historiador historicista no puede menos que escribir: "la respuesta suena inevitable: con el vencedor".

4 Por ejemplo, Apel, quien declaraba no hace mucho ("Identidad contingente y responsabilidad histórica. Una conversación con Karl-Otto Apel", Debats, no. 39, marzo, 1992) "debo decir con toda sinceridad que no he entendido bien esa tesis del final de la historia, como tampoco he entendido nunca formulaciones como la del final del hombre o el final del sujeto. Siempre me han parecido exageraciones paradojicas típicamente francesas." 
producción insuperable, ¿qué dinamismo movería la historia? Si la lucha de clases es el motor de la historia, ¿qué la puede mover cuando aquel antagonismo desaparece? El discurso maoísta, tan anacrónico hoy, hablaba de contradicción principal y contradicciones secundarias, muchas de las cuales hubieran subsistido en el comunismo, pero la cuestión es si esa subsistencia, residual por definición, no está llamada a extinguirse, momento en el cual la pregunta reaparecería ya sin excusas ni prórrogas.

Pero ése ya no es, está claro, nuestro problema. La evidencia que se ha ido abriendo paso en los últimos tiempos es de otro signo. No procede, desde el punto de vista filosófico, lamentarse diciendo: sería muy triste que el final de la historia se produjera en un modo de producción antagónico, en el que hay lucha de clases, explotación del hombre por el hombre y todo el caudal de sufrimientos que de sobra conocemos. O hacer como Levinas, cuando manifestaba recientemente: sería una pena (y no una victoria del espíritu) que se perdiese la esperanza que representaba el marxismo. Hace años, Horkheimer anticipó la respuesta a estos lamentos formulándose dos preguntas: " ¿acaso es la monstruosidad un argumento convincente contra la afirmación ó la negación de un estado de cosas? ¿Posee la lógica una ley al efecto de que un juicio sea falso cuando su consecuencia sea la desesperación?". En este punto, sólo cabe ser estoico (o pesimista): la necesidad y la desesperación no son formas de validez lógica.

Nuestro problema tiene que ver con el estado en que quedan aquellas cuestiones iniciales acerca de Marx, la modernidad y la historia tras todo lo que plantearemos a continuación. Porque las argumentaciones contra el carácter ideológico (por utilizar el viejo lenguaje) ${ }^{5}$ de la idea del final de la historia no han entrado en dos asuntos que forzosamente hay que plantear a la vez: el de cómo incide el fracaso del socialismo en la propuesta de Fukuyama y el de la vigencia o no de una perspectiva global para abordar lo histórico (con otras palabras, si la idea de totalidad y la idea de fin resultan inseparables).

5 He de confesar obvias dificultades teóricas para utilizar la categoría de ideología. Si bien es cierto que parece necesario pensar el tema mayor de la mediación social del conocimiento, los problemas aparecen cuando se desliza el supuesto de que no sólo existe dicha mediación, sino que además existe un lugar que es capaz de enunciar la mediación del conocimiento ajeno. Un lugar no mediado desde el cual uno postula que el discurso del otro es ideológico. Eso era algo relativamente razonable cuando lo que se oponía a la ideología era la ciencia. La ciencia aparecía como el lugar universal de conocimiento a salvo. Pero, en el momento en que el lugar ciencia no parece a salvo de la ideología, ¿desde dónde se dictamina la condición ideológica del otro discurso? Todavía quedaba una opción: decir que desde el lugar política. Habría en este supuesto un lugar llamado, por ejemplo, vanguardia del proletariado que estaría por encima de los demás en la historia. Pero semejante hipótesis ha hecho, si cabe, más crisis que la primera. Este planteamiento resulta, como no podia ser menos, exageradamente sumario. Pero no creo que actualizaciones como la de Habermas, al proponer una teoría de las ideologías concebidas como distorsiones sistemáticas de la comunicación por efecto de la violencia, modifiquen en lo sustancial mi reserva. 
1) Respecto a lo primero, nunca está del todo claro, ya sé, lo que vienen a probar los hechos: qué parte de nuestro discurso hacen buena y qué otra dejan invalidada. Pero en cualquier caso resulta difícil no tener cierta sensación de abuso cuando los mencionados hegelianos de derecha utilizan la derrota de ciertas experiencias históricas como argumento que hace buena nuestra realidad. La supervivencia de ésta sólo habla de su fortaleza, pero no nos dice nada de sus otras cualidades, que, si procede, deberán ser analizadas desde otro lugar teórico.

Otra variante de esta misma actitud la protagonizan aquellos que se esfuerzan por sancionar metacientíficamente lo ocurrido. Su empeño por transformar el fracaso de los países del socialismo real en refutación se diría que está relacionado con su deseo de presentar dicho fracaso como un destino o, aún mejor, como una necesidad. Probablemente porque consideran que la refutación de aquello equivale, a la inversa, a la verificación de esto, con otras palabras, a la garantía de su mantenimiento. Es cierto que la derrota del tradicional enemigo histórico les facilita mucho la tarea, pero ésta es una cuestión que no debiera confundirse con el análisis teórico del suceso. En vez de precipitarse en anunciar sonoras superaciones o refutaciones - según pertenezcan a la facción liberal-hegeliana o liberal-popperiana de la causa- más les valdría que se atrevieran a responder juiciosamente a la pregunta isigue siendo el mundo, en lo esencial, tal y cómo lo describió Marx?, o, lo que viene a ser lo mismo, ies el caso, realmente, que lo entendamos mejor sin su ayuda? No pretendo ejemplificar uno de esos ejercicios, tan conocidos en la metodología de la ciencia, de protección de la teoría de cualquier elemento falsador. El ejercicio, por cierto, sería aquí perfectamente viable: bastaría con recordar el tópico de "la venganza de Marx" y considerar todo lo ocurrido en los países del Este como su último y definitivo episodio, para que la presunta falsación quedara incorporada a la propia doctrina. ${ }^{6}$

Una respuesta sensata pasaría por el reconocimiento, que los conservadores más inteligentes no tienen inconveniente en plantear, de la aportación que ha hecho el marxismo en el conocimiento del modo de producción capitalista. ${ }^{7}$ Pero esa respuesta se vincula con una distinción sobre la que

6 Dos observaciones. La primera, que es un tópico de la epistemología que ninguna teoría es contrastable tal cual, sino por medio (esto es, con la ayuda) de enunciados intermedios. La segunda, que hay que pensar ese vínculo en nombre de, a su vez, por un doble motivo. Porque no hay pensamiento que resista si lo juzgamos a la vista de lo que se ha hecho con él y porque no hay pensamiento, ni siquiera cientifico, que lleve incorporado un manual de instrucciones que nos indique qué podemos hacer con él.

7 Como muestra de una posición abiertamente favorable al capitalismo, pero que no rehúye asimilar las proposiciones marxistas susceptibles de comprobación empírica, véase Peter L. Berger, La revolución capitalista, 2a. ed., Península, Barcelona, 1991. 
resulta obligado reflexionar. ${ }^{8}$ Ahora podemos examinar bajo una nueva luz la articulación entre los elementos descriptivo, valorativo y prescriptivo del marxismo que en algún momento se propuso. ${ }^{9}$ Me refiero a la tesis de que el marxismo articulaba de una forma particular los niveles descriptivo, valorativo y prescriptivo. Según ella, en El Capital coexistían simultáneamente tanto teorías o hipótesis teóricas en sentido fuerte cuanto valoraciones y fijaciones de objetivos o fines programáticos de conducta política. Se suponía que lo metodológicamente nuevo y relevante en este caso era que la totalidad del producto teórico estaba enfocada al servicio de la misión histórico-emancipatoria de la clase obrera, de tal manera que el análisis realizado y el programa político-social propuesto venían indisolublemente ligados, siendo esta unidad y su carácter revolucionario lo específico del marxismo. Lo que no significaba, claro está, que los elementos componentes de dicha unidad no pudieran ser diferenciados, como ya había visto el propio Marx: "En cuanto al libro en sí [El Capital] conviene distinguir dos cosas: los desarrollos positivos [...] que propone el autor, y las conclusiones tendenciosas que saca. Los desarrollos constituyen un enriquecimiento directo para la ciencia, puesto que las relaciones económicas reales son tratadas en él de una forma enteramente nueva, siguiendo un método materialista" (carta de Marx a Engels del 7 de diciembre de 1867).

Quizá ahora estamos en condiciones de percibir hasta qué punto, al hacer este orden de afirmaciones, estábamos atribuyéndole a Marx y al marxismo lo que en realidad ha sido una vieja aspiración del conocimiento en general desde siempre: ser algo más que mero conocimiento. Cabría citar, a título de ejemplo, la valoración que hace Feyerabend de La orestíada. En ella, se nos dice en "Diálogo sobre el método" (p. 191), se combina la exposición factual de condiciones sociales con la crítica de esas condiciones y la sugerencia de una alternativa, es decir, se piensa a la vez la tríada descripción-valoración-prescripción. O el conocido dictum de Aristóteles: la tragedia es más filosófica que la historia porque no sólo informa de lo que ocurrió, sino que además explica por qué tenía que ocurrir.

Pues bien, es precisamente la distinción (en cierto modo recuperada) entre los elementos descriptivo, valorativo y prescriptivo del marxismo la que nos aboca al siguiente paso: lo que ha hecho crisis ha sido el objetivo fijado, el fin propuesto. No ha habido refutación sino rechazo. Un acto de voluntad aplicado a alterar el planeado curso de los acontecimientos. El baremo que hay que utilizar no es el de la resistencia de la teoría a las falsaciones,

8 Michelangelo Bovero se refirió a este asunto en la conferencia inaugural del ciclo Perché rileggere Marx, oggi, organizado por el Departamento de Estudios Políticos de la Universidad de Turín (Turín, mayo del 92), y que aparecerá publicada próximamente en la revista Teoría política.

${ }^{9}$ La alusión tiene algo de autocrítico. Me referí a esta propuesta en mi libro La crisis del stalinismo: el "caso Althusser", Península, Barcelona, 1977, pp. 301-302. 
sino la de los individuos a las situaciones. Tenía razón Aron (Dimensiones de la conciencia histórica) al quejarse de la injusticia que suponía juzgar el capitalismo por sus faltas o insuficiencias y hacerlo con el socialismo por su intención última. La queja requiere hoy algunos retoques sustanciales para no incurrir, mecánicamente, en la injusticia contraria. Al socialismo real hay que oponerle, como su correlato, el capitalismo real. ${ }^{10} \mathrm{Y}$ si aquél pudo ser transformado como resultado de la acción humana colectiva, nada impide pensar que esa misma instancia pueda intervenir en las sociedades antagónicas por excelencia.

Conviene recordar estas cosas porque, con sospechosa frecuencia, las críticas a la posibilidad de conocer científicamente la historia y, por tanto, de predecir el futuro, se detienen ante las anticipaciones de cierto tipo. Si la historia es efectivamente imprevisible, ello habrá de afectar también, por lógica, a la predicción de su finalización, que quedará de inmediato vaciada de sentido. El fracaso del socialismo, por su parte, ejemplifica dicha impredicibilidad de manera casi perfecta, ${ }^{11}$ pero habría que ir con cuidado en no conformarse con la sola constatación. De poco sirve aludir a los múltiples errores de las predicciones existentes en el pasado, porque nadie queda a salvo de ellos. Cuando las cosas se planteaban en términos de pugna entre conservar y transformar no se contemplaba la opción agnóstica. El interés por conocer el futuro era compartido por unos y por otros: lo que variaba era el signo que se deseaba atribuirle. No se trata de que unos se hayan equivocado más que otros, se trata de que unos han perdido mucho más que otros con el error. Pero lo que aquí importa, lo que más me interesa subrayar, es que tales errores no se han dado en el vacío o porque sí, sino que han sido errores causados. Ésta es, pues, la rectificación: el futuro no se predice, se produce.

Así pues, entender la impredicibilidad obliga a dar entrada en el esquema a los agentes, a esos sujetos que intervienen mediante su acción en el curso de la historia. Y no porque sus conductas sean irracionales o ajenas a todo proyecto o planificación. Lo que ocurre (entre otros muchos factores, como

10 La confrontación, por supuesto, nunca puede ser en crudo, sino mediante nuestros esquemas interpretativos. Pero, aún así, ciertas realidades nos colocan ante la evidencia de otras. Por decirlo con las palabras de Cristopher Lasch: "la quiebra de los sistemas socialistas de la Europa del Este no nos debe engañar sobre las posibilidades reales del capitalismo. [...] todo parece indicar que Inglaterra y Estados Unidos están dispuestos a tolerar altos niveles de desempleo, el debilitamiento de la clase media y el crecimiento de una sociedad polarizada entre dos clases, la de los muy ricos y la de los muy pobres", en "Señores, apéense: el progreso ha terminado", La Vanguardia, 15 de mayo de 1990. Habrá que ver, ahora que se ha quedado solo, cómo encara el capitalismo estas situaciones -y cómo consigue interpretarlas el liberalismo.

11 Hace pocos años, resultaba perfectamente fácil tropezarse con afirmaciones del tipo: "los regímenes del socialismo real, a pesar de su proclamada esclerosis, podrían durar, con pequeños ajustes, hasta el infinito". El propio I. Berlin, en alguna entrevista periodística reciente, reconocía su completo error en lo tocante a la misma predicción. 
es obvio) es que la coincidencia desigualmente armónica o conflictiva de los múltiples fines da lugar a un resultado a menudo distinto a, y no reducible a la mera suma de, los objetivos particulares. Se reparará en que he utilizado expresiones como "nada impide pensar" y en que me he referido, sin más, a capacidad de intervención. Intentaba con ello anticiparme al reproche de ingenuidad y/o voluntarismo que alguien podría dirigirle a lo que estoy planteando. Tampoco quisiera incurrir en la idea de un sujeto histórico colectivo o transindividual, que hiciese la historia a la manera en que un artesano hace, digamos, un par de zapatos. Una idea tal hipostasia ilegítimamente a un metasujeto que es simplemente un individuo ideal. También en este caso los efectos posteriores de la teología se hacen evidentes, porque el prototipo obvio de tal metasujeto era Dios. Un enfoque más satisfactorio - investigaría la posibilidad de la construcción intersubjetiva y no coercitiva de un consenso cultural y social, evitando la mistificación que acompaña las ideas de supersujeto, de cualquier tipo que ellas sean. ${ }^{12}$

El referente polémico al que, de una u otra forma, todo lo anterior no deja de remitirse es ese juicio, no siempre explícito, que los acontecimientos de los últimos años han contribuido a sedimentar. Ese juicio que de la crisis del comunismo histórico infiere la no proyectabilidad de ningún orden social. En realidad, apenas he intentado hasta aquí otra cosa que argumentar a favor de la posibilidad, entendida como el espacio para la materialización de los fines, como el ámbito que convierte en inteligible (en este caso por verosímil) la acción humana, impidiendo el desfallecimiento ante los problemas del conocer y del obrar. Otro tipo de consideraciones, referidas, por ejemplo, a las efectivas probabilidades que una concreta propuesta programática de transformación de determinadas formaciones sociales pudiera tener, desbordaría con mucho el marco de lo que he pretendido abordar en este texto.

Parece defendible, en consecuencia, una perspectiva que, intentando asumir una autocrítica radical, no desemboque en el escepticismo o en la desesperación (variantes de lo posmoderno). Este convencimiento es algo más que una apuesta. Disponemos de alguna evidencia para echar a andar: el pasado nos importa, y desde algún lugar deberíamos dar cuenta de este interés. Dicho lugar lo podríamos nombrar por medio de una interrogante: si en la historia ya no pudiera ocurrir nada nuevo, ¿valdría la pena seguir estudiándola? La irrelevancia del pasado, parece claro, se dictamina desde determinada concepción del presente y del futuro. Resulta problemático aceptar que una sociedad pueda vivir sin conciencia histórica, del mismo modo que nos cuesta imaginar que un individuo pueda vivir sin memoria. Lo que pasa es que el nuevo camino por roturar (la nueva legitimación de

12 Tal y como comenta Martin Jay en su Fin-de-siècle socialism, Routledge, Nueva York, 1988 , pp. $80-81$. 
la historia) deberá hacerse a pasos pequeños porque nos hemos quedado definitivamente descalzos de las botas de siete leguas (las antiguas grandes palabras, las antiguas grandes categorías).

2) Entiendo que lo que hay que rechazar son esas macroteleologías, sean del signo que sean. La denominada posmodernidad ha llamado la atención sobre la debilidad de muchos de los conceptos y valores básicos del discurso occidental. Deberíamos retomar lo mejor de este aviso. Repensar el sentido de la historia desechando definitivamente muchos presupuestos tal vez ideológicos (con las reservas mencionadas) que operaban en nuestro tratamiento de lo humano.

Pensar de otra manera, si ello es lo que finalmente acordamos que se debe pretender, pasa en primer lugar por rechazar esa figura que se nos proponía del final de la historia. Aplicándole su propio cuento: lo que ha llegado a su fin es el fin de la historia. Esto no es una pura tautología, aunque pueda parecerlo. He vuelto sobre este tema para introducir en mejores condiciones aquella otra afirmación de Vattimo, de idéntica apariencia: "si la historia debe tener algún sentido, éste hay que buscarlo en la pérdida del sentido". ${ }^{13}$ La obsolescencia de las viejas maquinarias productoras de sentido nos ha permitido descubrir nuestra persistente necesidad de él. Desechadas las ideas de progreso, salvación o emancipación, y las metahistorias (Lyotard) que las albergaban, nos encontramos a solas y de frente con nuestra incapacidad para prescindir de una concepción unitaria de la historia en la que poder proyectar el futuro, tomar decisiones... y entender el pasado. ${ }^{14}$

Porque un acontecimiento cualquiera cobra sentido al comprenderse como un elemento que desempeña una función en un todo que lo abarca. En tanto ese todo abarca asimismo los antecedentes temporales, se está deslizando la idea de que nuestra actualidad constituye el extremo de acá de un único segmento en el que se incluyen todos los episodios de la historia anterior, sin posibilidad de introducir en ese pasado ningún tipo de rupturas o saltos bruscos. Cualquier reserva con efectos retroactivos acerca de la continuidad de lo precedente amenazaría la inteligibilidad de lo que

13 G. Vattimo, "El fin del sentido emancipador de la historia", El Pals, 6 de diciembre de 1986. Por las mismas fechas, Lyotard se manifestaba en un sentido extraordinariamente próximo: "si ninguna intervención política es capaz de suscitar sentimientos de entusiasmo, esto significa que la política no está dando signos de historia. Al mismo tiempo, sin embargo, precisamente los demás signos (la melancolía, la tristeza, la duda) nos dicen que en el escenario de la historia está sucediendo algo, y este algo es la desilusión por las viejas ideas de progreso de la humanidad. Y esto también puede ser un progreso", "A favor del entusiasmo. Entrevista con Jean-François Lyotard", El País, 11 de diciembre de 1986.

14 'Hacerse cargo del final de los 'metarrelatos' no significa, como para el nihilismo reactivo y vengativo descrito por Nietzsche, quedarse sin criterio de elección alguno, quedarse sin hilo conductor" (G. Vattimo, Ética de la interpretación, Paidós, Barcelona, 1991, pp. 35). 
ahora hay. En efecto, por poner un ejemplo extremo, si esa ruptura o salto brusco estuviera muy próximo a nosotros, ¿en qué totalidad integraríamos el presente para que no careciera de sentido? Y también (no sé si añadir: sobre todo), ¿qué sentido tendría volver la vista hacia un pasado con el que ya no tendríamos nada que ver? En suma, ¿qué podríamos entender de un pasado al que previamente hubiéramos declarado por completo extraño?

El supuesto de la continuidad se nos aparece como uno de los supuestos mayores de la actividad historiográfica. No sólo porque sea condición de posibilidad de ella misma, sino también porque determina la calidad del conocimiento por elaborar. Como es obvio, continuismo no tiene por qué hacerse equivaler a subjetivismo. Cabe interpretar la totalidad de la historia en términos, v.g., muy próximos a los de cualquier disciplina científica. Debiera quedar claro que no hay ninguna objeción de principio contra la pretensión general de abordar la realidad histórica como una totalidad dinámica dotada de coherencia interna, en la cual cada una de sus partes condiciona y transforma a las demás, a la vez que cada parte es condicionada y transformada por el todo. Como tampoco la hay contra la práctica de aquellos historiadores empeñados en desentrañar el porqué del cambio social y dedicados sistemáticamente al asedio del problema de la transición de un sistema económico o de un modo de producción a otro. La cuestión es si una perspectiva y una práctica de este tipo explicitan suficientemente los problemas que la idea de totalidad/el supuesto de continuidad plantean. Así, ¿consideramos definitivamente inservible la noción de progreso, o le concedemos todavía algún margen de validez? ${ }^{15} \mathrm{O}$ : ¿qué ocurre con el tema del relativismo histórico? Y muchas más interrogantes que probablemente podrían quedar subsumidas en la cuestión mayor, en la pregunta de todas las preguntas. A saber: ¿desde dónde - y cómo- pensamos lo que hay (sea esto lo que sea) de una sola vez?

Frente a quienes han considerado la famosa afirmación de Nietzsche, en El caso Wagner, "la vida ya no reside en el todo" como una consigna (de la que se derivaban otras: no hay un solo gesto teórico que nos permita abarcar la totalidad; la totalidad misma ha estallado en mil pedazos, en mil fragmentos; la pretensión de pensar la historia en términos unitarios, el empeño por encontrar algún tipo de hilo conductor que atravesara el entero conjunto del pasado debía ser abandonado), de nuevo Vattimo ha planteado la cosa en términos más prudentes: "Creo que no podemos hacer ética y política sin una filosofía de la historia, aunque la única filosofía de la historia que es posible en este momento es la filosofía que narra la historia del fin

15 El mismo Apel, loc. cit., aunque acepta la premisa de que los grandes metarrelatos están hoy muertos, matiza: "en contraste con Lyotard, yo no sustentaría la opinión de que, por ejemplo, se ha agotado también la idea de progreso de Kant, aunque sí la idea del saber relativo a la marcha necesaria de la historia. Ésta ha muerto realmente y también la utopía vinculada a ella." 
de la filosofía de la historia; y esto no es [... ] un juego de palabras. Quiero decir: la única visión global de la realidad que nos parece verosímil es una visión que asuma muy profundamente la experiencia de la fragmentación [las cursivas son mías]. Claro que también ésta es una visión totalizante, pero que, sin embargo, toma en cuenta la noción de fragmento." ${ }^{16} \mathrm{Al}$ hacer este reconocimiento, Vattimo (no sé si sin querer) está declarando pertinente una sospecha: ¿por qué no considerar esta experiencia fragmentaria como una experiencia ella misma histórica? (a título de ejemplo: en el mismo sentido en que cabe constatar que la bibliografía acerca del fin del progreso se da, de modo recurrente, en épocas de crisis).

Aludía antes a la relación entre la creencia en un libro sagrado (de la historia) y una concepción del relato histórico entendido como la historia del poder, como el relato escrito desde la óptica de aquellos que finalmente han hecho realidad su proyecto. Pero al lado de ellos hubo otros, sin duda la mayoría, que nos abandonaron sin llegar a ver lo que soñaban, que nos dejaron como única herencia un inmenso mundo de lo que hubiera podido ser y no fue. Alguien tendrá que reclamar ese legado, a no ser que se pretenda convertir el discurso histórico en una dócil y aplicada gestión del olvido o en un disolvente de la memoria. Pero eso sería como empeñarse en querer abrir la puerta al revés (incluso si esa puerta, como diría un nietzscheano, fuera una puerta giratoria). Lo no realizado gravita sobre nosotros como una especie de trascendental, presente en todo momento, acaso como una idea reguladora para los más conscientes. Estoy pensando en la definición de la propia vida que hace el Valéry de Moralités, según la cual ésta no es tanto el conjunto de cosas que nos pasaron o hicimos (lo que supondría una vida extraña, enumerable, descriptiva, conclusa), como el de las cosas que no hemos conseguido o que nos han decepcionado. A estos efectos, tal vez la noción de identidad nos puede ser de utilidad. Si la noción de identidad puede servir para la articulación de una reflexión sobre la historia y una reflexión sobre la acción es porque, inexorablemente, llega ese momento en que hemos de determinar quiénes son los nuestros.

La teleología obtiene de este modo un fundamento más modesto, pero al tiempo más constante y profundo, que no se confunde con el compromiso moral o con la respuesta necesaria, aunque, como es obvio, no los excluya.

16 J.M. Herrera, J. Lasaga, "Gianni Vattimo, filosofo de la secularización", entrevista con G. Vattimo, Revista de Occidente, 1990, no. 127. Por lo que hace a la primera parte de la cita, se repite casi textualmente la afirmación en Ética de la interpretación, cit., p. 35. En cuanto a la segunda parte, aludiendo a la rememoración del sentido del ser en cuanto contenido de la noción de "transformación del ser", el mismo Vattimo ha declarado que si "la especialización de los lenguajes y de las esferas de intereses y la fragmentación de la existencia pertenecen a la modernidad (una conexión que no parece dudosa, si se piensa todavía en Max Weber), la rememoración del sentido del ser como base para la reconstrucción de significados unitarios de la existencia es un traspaso de los límites de la modemidad" ("Post-moderno, tecnología, ontologia", Micromega, 4/90, p. 88). 
La afirmación es, entiendo que nítidamente, otra. La de que los hombres no actúan tan sólo porque estén comprometidos con una situación que se ha vuelto insoportable o intolerable, sino animados por cierta visión de lo posible, de lo que todavía no es. O si se prefiere enunciarlo en forma de principio: lo aún no vivido moviliza a menudo más fuerzas que las obligaciones. ${ }^{17}$ Queda señalada de esta forma la diferencia respecto al tópico, tan en boga en los 80 , según el cual ninguna ideología política es ya capaz de generar entusiasmo colectivo porque la sociedad posmoderna carece no sólo de un proyecto histórico movilizador, sino también de una imagen global de sí misma (dos caras, en definitiva, de la misma moneda).

No creo, para terminar, que este tipo de tesis me vincule, más allá de talantes personales, con optimismos históricos o similares, escala para la que me declaro abiertamente incompetente. Resulta fácil, hoy, entender a Benjamin cuando le escribía a Scholem: "Los estímulos que el mundo actual me ofrece son demasiado débiles, y los premios del mundo futuro demasiado inciertos" (carta del 14 de marzo de 1939). Pero es que, si se me permite una última simplificación, este pesimismo era la contrapartida de su mesianismo, de los restos de una concepción providencialista de la historia. La presunción de un pasado no finalizado o no clausurado no significa que a los muertos se les pueda devolver la vida. La injusticia pasada ha pasado y está terminada. No habrá juicio final que redima del sufrimiento padecido: eso sólo lo puede aguardar el pensador religioso. Frente a él, como dice (de nuevo) Horkheimer, "el materialista se deja inundar por el sentimiento del abandono sin límites de la humanidad, que es la única respuesta verdadera a la esperanza en lo imposible". Y, podemos añadir, una vez que se ha empapado de ese sentimiento, se está en condiciones de encarar la pregunta: ¿qué hacer con el anhelo de los hombres por vivir en un mundo distinto?

17 Jean Duvignaud, en su libro La solidarité. Liens de sang et liens de raison, Fayard, 1986, ha mostrado la condición histórica de este principio, poniendo al descubierto simultáneamente los diferentes vínculos que unen a los hombres y constituyen la matriz de cualquier organización social. Formas diversas de solidaridad (desde la solidaridad del saber de la "República de las Letras" y del saber hacer de las corporaciones del siglo XIII, hasta las modalidades más recientes derivadas de la industrialización y la división del trabajo, pasando por las "errantes" o extraterritoriales, como el exilio y la marginalidad) en las que, más allá de los límites, se escenifica un poder hacer, una anticipación - a veces utópica- de lo posible. 